\title{
O ENSINO DE GEOGRAFIA MEDIADO PELA CATEGORIA “LUGAR”: a partir do saber tradicional da "panema"
}

\author{
Gelciane da Silva Brandão ${ }^{1}$ \\ Leandro Nogueira Batista ${ }^{2}$ \\ José Vicente de Souza Aguiar 3
}

\begin{abstract}
RESUMO
O artigo faz parte dos resultados da pesquisa que iniciou nos estudos realizados no Programa de Pós-Graduação em Educação em Ensino de Ciências na Amazônia, intitulada "Saberes Tradicionais e o Ensino de Ciências: um estudo de caso na comunidade ribeirinha Nossa Senhora Aparecida do Miriti - Parintins/Amazonas", cujo objetivo consistiu na discussão da ideia de lugar, a partir dos saberes tradicionais relativos à "panema" como uma forma de micropoder, porque atribui sentido para o povo que nele acredita. Ocorreu por meio da realização de diálogos como os moradores da comunidade, por meio do procedimento fenomenológico de investigação. Os resultados indicaram que há possibilidade de alteridade entre estes saberes no ensino da ciência geográfica, articulados à categoria Lugar, esse expandido em seu conceito como uma forma de micropoder. Conclui-se que o exercício de pensar essa categoria para o ensino da geografia escolar não significa abandonar o conhecimento científico, mas compreender que existem outras possibilidades de diálogo com o mundo, além das definições da ontologia ocidental, ao mesmo tempo que se torna possível entender como pessoas constroem suas percepções do lugar de existência e de vida.
\end{abstract}

Palavras-chave: Saberes Tradicionais; "Panema". Lugar.

\section{THE TEACHING OF GEOGRAPHY MEDIATED BY THE "PLACE" CATEGORY: as from the traditional knowledge of "panema"}

\begin{abstract}
The article is part of the results of the research that began in studies carried out in the Graduate Program in Education in Science Teaching in the Amazon, entitled "Traditional Knowledge and Science Teaching: a case study in the riverside community of Nossa Senhora Aparecida do Miriti - Parintins/Amazons". The goals were

1 Doutoranda em Educação na Amazônia - EDUCANORTE. Assessora Técnica na Universidade do Estado do Amazonas (UEA), Parintins, Amazonas, Brasil. Orcid iD: https://orcid.org/00000001-7577-3321.E-mail: gbrandao@vea.edu.br

2 Doutorando em Educação na Amazônia - EDUCANORTE. Membro do Grupo de Pesquisa: Fundamentos da Educação e Ensino de Ciências (GEPFEEC), Manaus, Amazonas, Brasil. Orcid iD: https://orcid.org/0000-0002-6069-0352. E-mail: leandrobatistta@outlook.com.br

3 Doutor em Educação. Docente da Universidade do Estado do Amazonas (UEA). Manaus, Amazonas, Brasil. Orcid iD: https://orcid.org/0000-0001-7754-1620. E-mail: jvicente@vea.edu.br
\end{abstract}


to constitute the discussion of the idea of place category from the traditional knowledge related to "panema" as a form of micropower that gives meaning to the people who believe in it. The research took place through dialogues with the community's residents, based on the phenomenological investigation procedure and the results indicated that there is a possibility of alterity between these knowledges in the teaching of geographic science, also articulating the category Place nd expanding its concept as a form of micropower. It is concluded that the exercise of thinking about this category for the teaching of school geography does not mean abandoning scientific knowledge, but also understanding that there are other possibilities of dialoguing with the world beyond the definitions of Western ontology, while it becomes possible to understand how the people build their owns perceptions of the place of existence and of the life.

Keywords: Traditional knowledge; "Panema"; Place.

\section{LA ENSEÑANZA DE LA GEOGRAFÍA MEDIADA POR LA CATEGORÍA "LUGAR": a}

\section{partir del conocimiento tradicional de la "panema"}

\section{RESUMEN}

El artículo es parte de los resultados de la investigación iniciada en los estudios realizados en el Programa de Postgrado en Educación sobre la Enseñanza de la Ciencia en la Amazonía, titulada "Conocimiento tradicional y enseñanza de la ciencia: un estudio de caso en la comunidad ribereña Nossa Senhora Aparecida do Miriti - Parintins/Amazonas", cuyo objetivo fue discutir la idea de lugar a partir del conocimiento tradicional relacionado con el "panema" como una forma de micropoder que da sentido a las personas que creen en él. Se produjo a través de diálogos con los residentes de la comunidad, a partir del procedimiento de investigación fenomenológica. Los resultados indican que hay posibilidad de alteridad entre estos saberes en la enseñanza de las ciencias geográficas articulando la categoría Lugar, ampliando su concepto como forma de micropoder. Se concluye que el ejercicio de pensar esta categoría para la enseñanza de la geografía escolar no significa abandonar el conocimiento científico, sino entender que existen otras posibilidades de diálogo con el mundo más allá de las definiciones de la ontología occidental, en tanto que se hace posible comprender cómo las personas construyen sus percepciones del lugar de la existencia y de la vida. Los resultados indican que hay posibilidad de alteridad entre estos saberes en la enseñanza de la ciencia geográfica articulando la categoría Lugar, ampliando su concepto como forma de micropoder. Se concluye que el ejercicio de pensar esta categoría para la enseñanza de la geografía escolar no significa abandonar el conocimiento científico, sino entender que hay otras posibilidades de diálogo con el mundo más allá de las definiciones de la ontología occidental, en tanto que se hace posible comprender cómo las personas construyen sus percepciones del lugar de la existencia y la vida.

Palabras clave: Conocimiento tradicional; "Panema". Lugar. 


\section{INTRODUÇÃO}

Os estudos realizados no Programa de Pós-Graduação em Educação em Ensino de Ciências na Amazônia, da Universidade do Estado do Amazonas (UEA/2019), tiveram continuidade nas discussões e reflexões promovidas na disciplina "Estudos de Problemas educacionais da Amazônia", do doutorado em Educação na Amazônia, do Programa de Pós-Graduação em Educação na Amazônia - PGEDA - Associação em Rede (EDUCANORTE). Ou seja, uma preocupação de pesquisa do mestrado encontrou ressonância nas leituras e discussões realizadas no doutoramento em educação na Amazônia.

A pergunta de pesquisa visou responder: há possibilidade da categoria geográfica "lugar", ser significada a partir do saber tradicional da "panema", como um micropoder? Já seu objetivo consistiu na possibilidade de trabalhar - conceito da categoria geográfica "lugar", a partir do conceito de micropoder da "panema", no ensino de geografia.

Para o antropólogo Eduardo Galvão (1951, p. 222) a "Panema é comumente definida como falta de sorte, azar, infelicidade" e foi com esse sentido, incorporada ao vocabulário popular do Norte, correspondente a uma força mágica, impessoal que "[...] "infecciona" homens, animais e objetos", por isso esse fenômeno "mágico" e de "encantamento (GALVÃO, 1951), refere-se a um pensamento que pode ser compreendido como um micropoder, isto na perspectiva abordada por FOUCAULT (2008). Além do mais, é perceptível que faz sentido para determinado povo, principalmente na Amazônia e, sobretudo, para aqueles que têm suas vidas em contato com os rios e as matas.

Por sua vez, o lugar, na Geografia, é descrito pela vivência, pertencimento e "é uma teia de objetos e ações com causa e efeito" (SANTOS, 1994, p. 97) sentidos pelo viver, seja em uma comunidade amazônica, seja em uma cidade, como também em uma casa relativos a vínculos de pertencimento. O fato é que ele não tem uma dimensão medida em escala, exclusivamente mensurável pelas coordenadas geográficas, porque se constitui pelo mundo da vida, pela relação entre o humano e a natureza, que são indesatáveis. 
Para se chegar aos resultados, utilizamos como método de abordagem a fenomenologia baseada na obra Fenomenologia da Percepção, de Maurice Merleau-Ponty (1999), que nos proporcionou, no campo da pesquisa, o exercício de uma ação compreensiva diante de saberes da vida, que quase sempre são relegados à condição do não-científico.

A forma como os agentes sociais acreditam na força "panema" pode ser compreendida como uma reconfiguração do conceito de lugar para o ensino da geografia de comunidades ribeirinhas. A partir da categoria êmica "panema", como uma força invisível que é sentida no corpo e exerce forte influência em suas atividades laborais. Nesse sentido, os agentes sociais da Amazônia não podem reduzida à escassez de peixe que faz com que o pescador não o pegue, por exemplo, mas sim à força da "panema", um micropoder que existe e é exterior ao corpo daquele que acredita nela. Isto tem relação com o sentido de lugar. Nesse universo de compreensão, a natureza tem poder e é um ente que tem força para agir sobre o homem.

\section{METODOLOGIA}

A pesquisa foi desenvolvida na comunidade Nossa Senhora Aparecida do Miriti (FIGURA 1), cerca de $17 \mathrm{~km}$ distante da cidade de Parintins - AM, levando em consideração que o Centro de Estudos Superiores de Parintins da UEA está a S 02 35' 51.9" e W 056³6'03.3" (IBGE, 2019).

FIGURA 1 - Comunidade N. Sra. Aparecida do Miriti em Parintins/AM

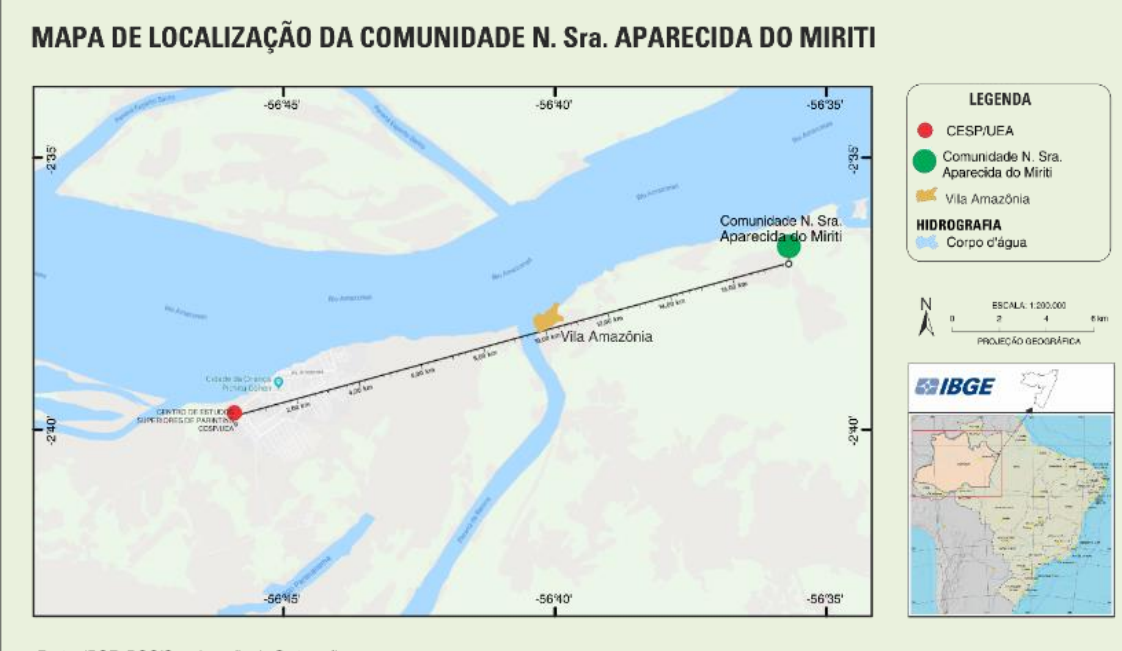

Fonte: IBGE (2019). Organização Gelciane Brandão 
A pesquisa se desenvolveu com descrições da realidade vivida de cinco agentes sociais. Utilizamos como método de abordagem $\mathrm{O}$ fenomenológico, baseado no filósofo Merleau-Ponty (1999, p. 03), a fim de não objetivarmos seus saberes, pois "[...] tudo aquilo que sei sobre o mundo, mesmo por ciência, eu sei a partir de uma visão minha ou de uma experiência do mundo sem a qual os símbolos da ciência não poderiam dizer nada".

A pesquisa de campo com aporte da percepção fenomenológica foi realizada durante cinco encontros com os agentes sociais, em média de sete dias para cada um, nos quais foram realizados os diálogos e as entrevistas sobre a temática "panema" e a observação das experiências de vida na relação sobre homem e natureza. Esse procedimento possibilitou construir informações para compreensão e posterior descrição da fala sobre a categoria "panema".

Para dialogar com a percepção fenomenológica dos agentes sociais sobre a "panema", utilizamos as ideias de Michel Foucault (2008), referente às modalidades enunciativas: Quem fala? De onde se fala? Por que fala? Para quem fala?

A fenomenologia de Merleau-Ponty (1999) está presente na descrição da percepção dos agentes sociais por meio de suas falas. Por sua vez, as modalidades enunciativas de Foucault (2008) foram usadas para a organização das ideias, realizando a tessitura da "panema" relativa a um micropoder (FOUCAULT, 1979), problematizando assim o conceito de lugar no ensino da Geografia escolar.

\section{A "PANEMA" DESCRITA POR EDUARDO GALVÃO (1951)}

O antropólogo Eduardo Galvão (1951) nos ajuda a compreender a crença da "panema" segundo a ótica do que ele denominou de caboclo amazônico. A partir da premissa desse indivíduo, é possível notarmos seu "[...] tipo físico, como na sua cultura, o caldeamento de elementos de origem ibérica e ameríndia. Um terceiro elemento, o africano, também contribuiu para essa formação, porém em proporção menos significativa que aqueles dois primeiros" (GALVÃO, 1951, p. 221). 
Nesse contexto, considera-se que as crenças fazem parte da cultura amazônica, mas sua origem remonta à herança ibérica, africana e indígena, assim como consiste num saber que se funde e apresenta incorporações modernas, que não sabemos precisar a sua origem, mas como ressalta Galvão (1951, p. 222) é "uma coisa nova" porque são crenças que estabelecem relação com a floresta ou com os rios:

\begin{abstract}
Assim, por exemplo, as crenças em seres da floresta ou dos rios como - Curupira, Matintaperera, Anhangá, o boto ou a iara, as "mães", onde a providência ameríndia, e mais especificamente, tupi ou tupinizada, é evidente. Observa-se, porém, que mesmo essas crenças estão longe de seu molde original, apresentando-se hoje impregnadas e transformadas por elementos de origem diversa. É notória, por exemplo, nas descrições daqueles seres, a origem ibérica de conceitos como "encantado", "louros e alvos", sua identificação ao lobisomem, como na própria tentativa de controlá-los através de rezas, invocações, uso de água benta e imagens de santos (GALVÃO, 1951, p. 222).
\end{abstract}

Essas crenças possuem um sentido para o povo que acredita na força delas. Isto é necessário que seja percebido a partir da subjetividade do outro, ou seja, naquilo em que ele acredita e faz sentido para a cultura de um povo. Galvão (1951, p. 222) destaca ainda que as crenças "[...] para uma grande parte da população amazônica rural são importantes porque orientam o indivíduo nas suas relações com o mundo que o cerca, uma vez que se destaca porque está ligada à vida diária do indivíduo", isso afeta principalmente os seus meios subsistência. Mas não se trata apenas de uma crença desprovida de sentido, pois ela serve de orientação para a vida na relação com a natureza. Ou seja, consiste num conhecimento que orienta a vida.

Segundo Galvão (1951), o sentido de "panema" advém de uma "força mágica", não se refere a uma pessoa em particular, por isso considerada "impessoal", podendo atingir o homem, os animais e os objetos, tornando-o incapacitado para exercer a sua função a qual costumeiramente exercia com sucesso, e cita ainda que: 
Não é apenas uma falta de sorte ou infelicidade ocasional, porém, uma incapacidade temporária que aflige o indivíduo ou objeto, um processo cujas causas e sintomas podem ser determinados e são conhecidos. Um pescador ou caçador cujo insucesso repetido não pode ser explicado por causas ou circunstâncias que ele considera "naturais", a época impropria, a qualidade de seus petrechos, etc., atribuirá o fracasso à panema, sua própria, de sua linha, carabina ou que outros objetos estejam usando. O cachorro que o acompanha na mata, a canoa em que se transporta, podem ficar panema (GALVÃO, 1951, p. 223).

A partir da percepção se sabe qual o corpo está portando a "panema", se ela está no homem, no animal, ou em algum objeto utilizado no cotidiano de sua prática laboral, e "[...] procura-se evitar o contágio dos corpos pela "panema", recorrendo a uma série de técnicas preventivas. Quanto a elas, incluem banhos e defumações em que o uso da pimenta e do alho são os principais produtos, ao lado de um sem número de ervas, "resguardos" e abstenções de determinados alimentos" (GALVÃO, 1951, p. 223).

Em outras palaras, nessa citação, observamos a pimenta como elemento de prevenção, no entanto é variável, porque identificamos na fala de um dos agentes sociais da pesquisa realizada em 2019 que a pimenta também pode ser a causadora da panema, a saber: "Tinha um primo que não gostava de levar pimenta para o lago porque empanemava ele" (ESPERANÇA/85, entrevista 2019). Nesta passagem podemos observar que o saber tradicional pode apresentar novas formas, reinventando-se no tempo e no espaço. Isto é, a "panema" destacada por Galvão, em 1950, juntamente com os produtos a serem utilizados para o seu combate, é reinterpretada. $O$ seu poder continua a existir, mas a interpretação se apresenta de forma diferente.

A fonte da "panema" pode variar, mas realiza-se por meio de um processo de eliminação daquilo que eles sentem no corpo ou a partir de suas percepções sobre o mundo vivido, quais são os riscos em potencial. A esse respeito, Galvão (1951, p. 223) registrou que as fontes mais comuns são:

[...] mulher grávida que se alimenta da caça ou do peixe apresados por um indivíduo; mulher menstruada que toca um dos petrechos do caçador ou pescador, arma, linha, anzol, etc.; desconfiança, mal 
estar entre amigos, especialmente por cobiça de alimentos; ossos ou espinhas abandonados no terreiro ao alcance de cachorros, porcos e animais domésticos; feitiçaria (Grifos dos autores).

Essas fontes da "panema" são atribuídas principalmente às mulheres, e, quando se encontram grávidas, são consideradas mais fortes, como demonstram os relatos da pesquisa de Brandão (2019, grifo nosso), "Uma mulher gestante que come imbiara, a caça que ele matou, empanema" (MARIA/82, entrevista 2019). "Se mata um pirarucu, a mulher gestante come, empanema o pescador" (MARIA/82, entrevista 2019). "A pior panema é da mulher gestante, que só vai passar depois do bebê sair" (JOÃO/58, entrevista 2019).

Galvão (1951) descreve que pescadores e caçadores, por receio da "panema", certificam-se a quem estão vendendo os seus produtos, sobretudo para que mulheres grávidas não venham a comê-los, ainda que involuntariamente, uma vez que a pessoa empanemada recorrerá ao processo de cura, o que pode ocasionar efeitos negativos à mulher grávida, podendo inclusive fazer com que haja a perda do filho. "É justamente os efeitos da cura que temem, pois acreditam que ao curar-se da "panema", a mulher sofrerá um aborto ou a criança nascerá pelada, "descascado", para morrer com pouco dias de vida" (GALVÃO, 1951, p. 223).

É natural que o caçador ou pescador acometido pela "panema" vá em busca de tratamento imediato de si ou de seu apetrecho, que pode ser uma canoa, um facão, uma espingarda, uma malhadeira, um arpão etc. No entanto, como já mencionado o procedimento, pode acarretar consequências graves para mulher grávida, nesses casos de certeza da fonte, por questões éticas "[...] ele deve procurar a mulher e pedir-lhe que venha ela mesma curá-lo, única maneira de não lhe causar mal" (GALVÃO, 1951, p. 224).

Outro caso relatado por Galvão (1951) consiste da mulher menstruada. Mas nesse cenário, o indivíduo pode recorrer ao processo de cura sem causar nenhuma consequência negativa a ela. Uma vez conversado com a mulher que foi fonte da "panema", o pescador ou o caçador solicita que ela faça o seguinte procedimento: 
Ela tinha que mastigar a linha de pesca com a boca cheia de pimenta, deixar escorrer a baba de pimenta sobre o anzol. Se isso falhasse, a panema estava nele mesmo. Deixava de pescar por algum tempo, pois se recorresse aos banhos e defumações, era certo a mulher sofrer as consequências. No caso de um caçado, a mulher mastiga a pimenta e deixa a baba escorrer pelo cano e pela alça de mira da carabina. Se ineficiente esse processo, o caçador deve abster-se de outros tratamentos para evitar à mulher (GALVÃO, 1951, p. 224).

Por esse motivo é recomendado e ensinado às mulheres grávidas que comam somente a caça ou o peixe que foi adquirido pelo marido ou outro membro da família, desde que antes de preparar o alimento ela realize o seguinte método preventivo: "[...] Antes de preparar a caça a mulher mastiga um pedaço assado de fígado do animal juntamente com um punhado de pimenta e deixa a baba escorrer sobre o fogo que vai assar a peça" (GALVÃO, 1951, p. 224).

A outra fonte da "panema" seria a inveja, proveniente entre dois amigos, o invejado pelo sucesso na pescaria ou na caçada fica como o empanemado; além disso, há os processos de feitiçaria: "[...] Para realizar seu intento basta ao indivíduo apoderar-se de um pedaço de caça ou peixe que motivou a desconfiança, e urinar ou defecar sobre ele. Mais simples pode atirá-lo em sua sentina ou fossa" (GALVÃO, 1951, p. 225).

Eles também acreditam que não é bom lavar as mãos sujas de sangue ou mesmo a presa que foi morta em igarapés ou no rio. "A "mãe" do igarapé ou do porto ficará ofendida e lançará "panema" sobre o indivíduo" (GALVÃO, 1951, p. 225). A lavagem da caça deve ser feita longe das margens, as sobras do animal tem de ser lançado na mata, mas com o cuidado de não ser um lugar onde transitam pessoas, pois se esses restos forem deixados em lugar transitável, pode ocasionar a "panema".

Finalmente, os métodos de cura variam de acordo com o saber de cada indivíduo, envolvem, sobretudo, "banhos ou defumações em que a pimenta e o alho são os principais componentes, ou seja, cipó alho, ninho de gavião cauré, folhas de aninga e uma variedade de ervas "fedorentas e cocentas" são sempre adicionados aqueles dois principais alimentos" 
(GALVÃO, 1951, p. 225). A quantidade de banhos ou defumações varia de acordo com o saber individual e da força da "panema".

Assim, a organização do conceito da "panema "por Eduardo Galvão (1951) nos revela que é um saber estruturado. Apresentamos na figura 02 esse cenário da seguinte forma: 1. Definição (enquanto uma incapacidade temporária que afeta o homem que caça ou pesca, animais e objetos utilizados na atividade laboral); 2. Fonte que advém de (mulheres grávidas ou menstruadas, da inveja...); 3. Técnicas Preventivas que envolvem (banhos com ervas e mulheres grávidas não podem comer da caça ou do pescado; e cuidados com os restos de animais); 4. Efeitos da Cura que pode causar em mulheres grávidas mal à criança, podendo nascer com deformidades e causar a sua morte; para isso aconselha-se quando a "panema" foi oriunda de uma mulher grávida, que está seja chamada para ajudar a desfazê-la, a isso Galvão (1951) chamou de 5. Ética; e 6. A Cura (que tem como elementos principais pimenta e alho, que são colocados nas defumações e banhos com ervas fedorentas).

FIGURA 02 - A organização da categoria amazônica "panema"

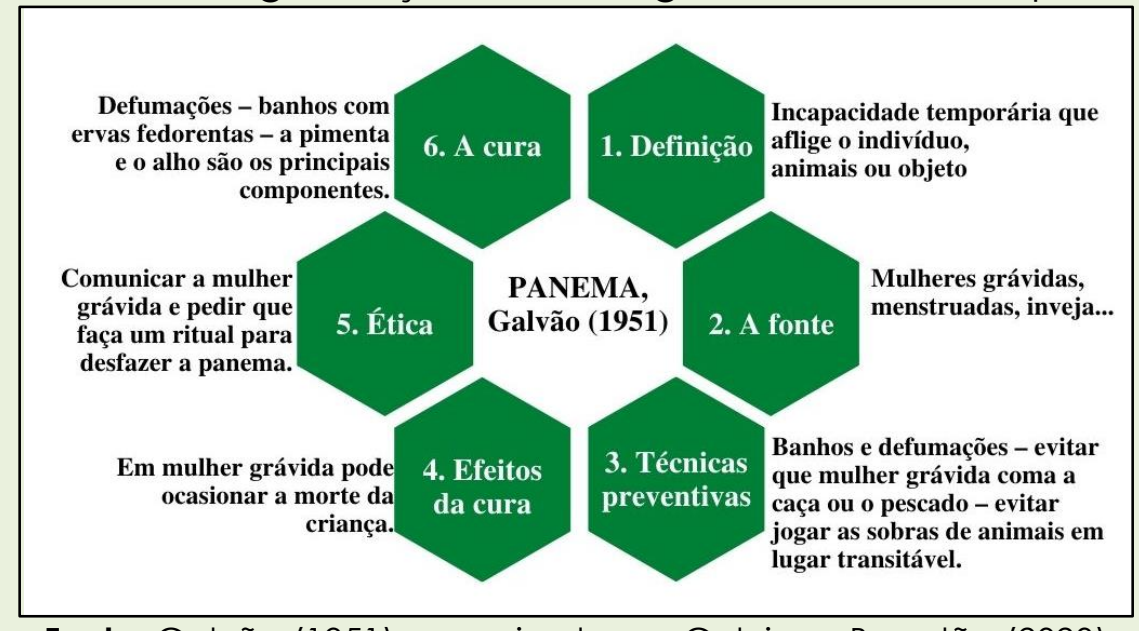

Fonte: Galvão (1951), organizado por Gelciane Brandão (2020)

Na figura 02, a "panema" é percebida como crença do homem amazônico e é manifestada em quem possui relação com a caça, a pesca, porque pode afetar o homem, os seus objetos usados em suas atividades laborais, animais e até mesmo plantas. "O conceito de panema está ligado 
às técnicas básicas de subsistência, e mais que outra crença qualquer, à vida quotidiana do indivíduo" (GALVÃO, 1951, p. 225). Nesse sentido, a panema está presente na categoria "lugar", na Amazônia, ou seja, não há lugar sem o conjunto de significações e relações estabelecidas entre homem e natureza. Daí a necessidade de inclusão desses entendimentos no ensino de geografia, sobretudo nas localidades em que essa categoria tem essa dimensão de significados representativos para o mundo da vida.

\section{A PANEMA PENSADA A PARTIR DAS MODALIDADES ENUNCIATIVAS DISCUTIDAS POR MICHEL FOUCAULT}

O filósofo Michel Foucault (2008), na obra Arqueologia do Saber faz uma história das ideias, sua preocupação central é diferenciar discurso de arquivo. O discurso seria "um número limitado de enunciados para os quais podemos definir um conjunto de condições de existência" (FOUCAULT, 2008, p. 143). Nesta obra percebemos a possibilidade de refletir sobre outras categorias, como as modalidades enunciativas.

FIGURA 03 - A "Panema" como um micropoder?

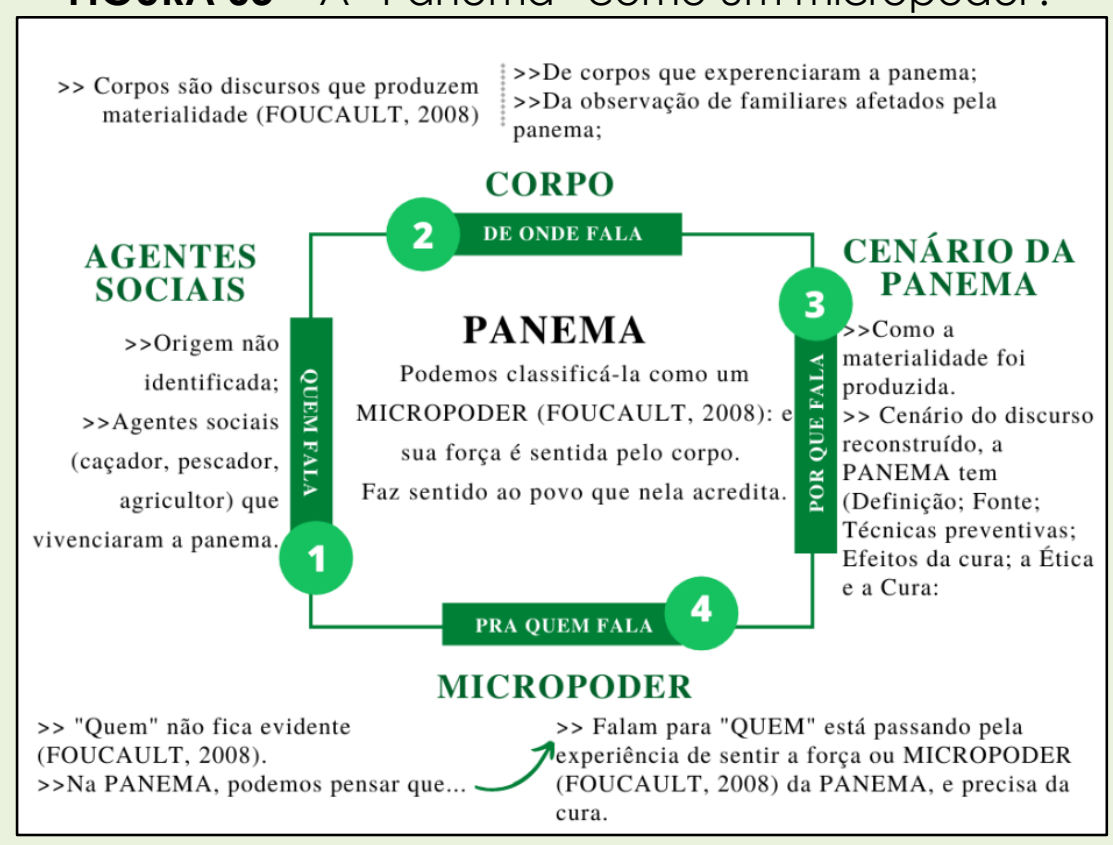

Fonte: Organização, Gelciane Brandão (2020)

As modalidades enunciativas aqui discutidas foram: Quem fala? De onde fala? Por que fala? Para quem fala? Junto a categoria amazônica "panema", como está representado na figura 03. 
Pensamos na organização do saber tradicional da "panema", junto a essa organização de modalidades enunciativas discutidas por Foucault (2008), confome demosntrado na figura 03, porque para ele o corpo é capaz de produzir materialidades distintas, de acordo com a ótica da abordagem arqueológica do discurso. Assim seguimos um percurso que faz uma breve, mas importante associação com a categoria amazônica "panema": quem fala (agentes sociais); de onde fala (corpo); por que fala (cenário da "panema") e para quem fala (não fica evidente/micropoder), micropoder que levarmos a discussão da categoria "lugar', ressignificando seu conceito no ensino da geografia escolar.

Para Foucault (2008), não há discurso exterior a uma relação, a uma interação social, assim ele acredita em um sujeito discursivo que, só é possivel ser desenvolvido na interação que ocorre no mundo vivido. Nós nos reconhecemos como sujeitos na relação com o outro, por esse motivo é imprescindível entendermos o que as instituições estão produzindo. Desta forma, as escolas não estão à margem desse processo, nem as comunidades amazônicas, por meio de seus agentes sociais, porque ensinam saberes relacionados à água, à terra e à floresta, em momentos diferentes, e produzem novas formas tradicionais desse saber (ALMEIDA, 2008).

Nessa perspectiva, a primeira modalidade enunciativa: quem fala? "[...] quem, no conjunto de todos os falantes, tem boas razões para estar nessa posição" (FOUCAULT, 2008, p. 56). Para compreendermos este saber tradicional da "panema", os agentes sociais estão nessa posição, pois são portadores de um saber que faz sentido para eles. Como não-viventes diretamente dessa experiência, não estamos na posição de falar por eles, mas descrever e analisar os fenômenos, a partir da fala individual.

Procurar identificar quem está expressando, determinado o discurso consiste numa estratégia de pesquisa e conhecimento do efeito de poder. Neste caso, podemos compreender como uma relação de poder positiva, faz com que os seres humanos e a natureza não sejam compreendidos de maneira separada. Logo, mesmo quando conseguimos localizar o sujeito da fala, não temos como localizar a emergência da ideia da "panema", porque 
o saber tradicional da "panema" é histórico e não conseguimos precisar a sua origem ou determinar um conceito único. Além de histórico é atual no universo das pessoas com quem a pesquisa foi realizada, pois a fala de dona Maria/82 (entrevista 2019) nos contou por meio de um exemplo o que é a panema: "O João vai pescar hoje e matou um pirarucu, na outra semana ele vai de novo e não pega nada, empanemaram ele, alguém que tem o olho doído, com inveja".

Quanto a segunda modalidade enunciativa: de onde se fala? "É preciso descrever também os lugares de onde o saber médico obtém seu discurso, e onde este encontra sua origem legítima e seu ponto de aplicação" (FOUCAULT, 2008, p. 57). Nesta abordagem, o autor arrisca construir uma ideia de espaço de fala, para ele prédios, corpos são discursos que produzem materialidades, ao mesmo tempo em que certos discursos ganham a legitimidade e o poder de construir verdades. Os agentes sociais acessam uma narrativa memorialística e imprimem sobre ela a ideia de verdade acerca dos fenômenos que acreditam, porque falam da comunidade onde experenciaram as causas do poder da "panema", e como esse corpo produz formas de agir, então os sintomas são descritos das seguintes formas pelos agentes sociais:

Uma vez meu marido pegou uma panema que a gente penou muito para comer. Ele ficou tão triste que ele chegou a pensar em cortar todas as malhadeiras dele. Mas ele ia pescar e não pegava nada, a gente padeceu fome, ele nunca foi de sair para pescar e voltar sem nada. Naquela época como não tinha gelo ele trazia de quatro tambaquis, então ele pegava uma linha, amarrava na boca do peixe e soltava no lago, pra gente comer de acordo com a necessidade que a gente tinha. Às vezes as pessoas vinham comprar, acho que foi assim que a pessoa ficou com inveja, aí foi que judiou das malhadeiras dele (ASSUNÇÃO 60, entrevista 2019, grifo nosso).

Já aconteceu comigo, de ver caça, atirar e parece que não tem nada, vai embora. Assim na pescaria também, quando eu pescava pirarucu, o peixe passava perto de mim, não tinha como errar, parece que não tinha nada, não tinha carne, não tinha couro, nada. Isso é a panema, é tão forte que o braço dói de tanto arpoar. Quando você pega no areio, que suspende uma haste, ela pesa $1 \mathrm{~kg}$ quando você levanta, e quando você aria a sensação é de que ela pesa $10 \mathrm{~kg}$ (JOÃO 58, entrevista 2019).

A tristeza, a dor são associadas ao efeito da "panema" no corpo dos agentes sociais que viveram ou observaram a sua ação em outra pessoa. 
Nesse cenário, a inveja é associada ao mau que prejudica os utensílios utilizados na pescaria ou na caça, ou mesmo ao homem e ao animal que o acompanha. Esses corpos produzem um discurso, ou seja, por meio de uma relação de poder que advém da falta de sorte nas atividades laborais, assim a "panema" "[...] se destaca por que está ligada à vida diária do indivíduo, afetando sobretudo seus meios de subsistência" (GALVÃO, 1951, p. 222).

O corpo humano manifesta a "panema" por meio da falta de sorte na pescaria, o corpo triste ver a caça e não consegue pegá-la; dói o corpo por conta das diversas tentativas mal sucedidas. Para a fenomenologia, "[...]० sensivel não tem apenas uma significação motora e vital, mas é uma certa maneira de ser no mundo que se propõe a nós de um ponto do espaço, que nosso corpo retoma e assume se for capaz, e a sensação é literalmente uma comunhão" (MERLEAU-PONTY, 1999).

$\mathrm{Na}$ terceira modalidade enunciativa: por que fala? "o sujeito questiona segundo uma certa grade de interrogações e ouve segundo um programa de informação, observa segundo um quadro de traços característicos" (FOUCAULT, 2008, p. 58). O cenário do discurso também é considerado e precisa ser reconstruído para entendermos como uma materialidade foi produzida. Neste caso, os agentes sociais são levados a serem objetos de análise, pois além da fala, eles são o lugar da fala, porque o corpo se expressa por meio da experiência da "panema" em seus corpos. Assim, descrevemos as causas (fonte) do poder da "panema", isto é, se eles falam é porque são conhecedores de uma experiência exterior e anterior a qualquer forma de entendimento desse mundo por eles vivido e significado a partir da experiência. Nesse sentido, o cenário do discurso reconstruído nos levou a registrar o que eles fazem para impedir o efeito da "panema":

Meu marido não leva panela para pescaria porque ele diz que empanema a pescaria. Aí ele não leva vasilha, traz o peixe dentro do casco e quando chega manda buscar lá na beira (ASSUNÇÃO 60, entrevista 2019).

Tem pescador que não gosta de entrar com sandália que dá panema (ASSUNÇÃO 60, entrevista 2019).

Fazer xixi encima da escama do peixe também empanema 0 pescador (MARIA 82, entrevista 2019). 
A causa da "panema" pode vir de mulher grávida que comeu a caça, de atitudes fisiológicas feitas em cima de restos dos animais pescados ou caçados, como também entrar com calçado, levar algum objeto ou pimenta. O tempo todo o corpo produz materialidade, significando suas ações, é o lugar da fala.

Em outras palavras, a relação com o corpo é a matéria afetada pelo panema, eles sentem, é a percepção vista do interior de uma forma de saber, válida para explicar o mundo vivido. A esse respeito, Merleau Ponty (1999, p. 253) destaca que "o sentido da fala é apenas o modo pelo qual ela maneja esse mundo linguístico, ou pelo qual ela modula nesse teclado de significações adquiridas. Eu o apreendo em um ato indiviso, tão breve quanto um grito".

A quarta modalidade enunciativa: para quem fala? "[...] observar a utilização de instrumentos que modificam a escala da informação, deslocam o sujeito ao nível perceptível médio e imediato, assegurando sua passagem de um nível superficial a um nível profundo" (FOUCAULT, 2008, p. 59). Esse "quem" não é alguém que recebe a informação direta de determinado discurso, não fica evidente no contexto da pesquisa. Mas, conforme fomos buscando realizar um diálogo com as modalidades enunciativas de Foucault (2008), considerando o saber tradicional da "panema", percebemos que, neste caso, o "quem" está evidente em quem acredita no poder da "panema", pois, é um processo que perpassa pelos agentes sociais por meio da oralidade e está na memória, seguido de seus corpos que experenciam tal poder, dentro de um cenário de lugar da fala que, ao ser reconstruído, registramos o que eles fazem para evitá-lo.

A partir dessa premissa indaga-se: Para quem fala? Para quem acredita no poder da "panema", na sua força de modificar a sorte da pescaria ou na caça, assim somos levados a conhecer a cura, conforme o relato a seguir: 
Eu já vi gente de panema, até um cachorro meu ficou assim, eu dava banho nele com folha de gipoóca ${ }^{4}$ é uma raiz, a gente bate e aquilo espuma, eu tratei e ele ficou bom (ESPERANÇA 85, entrevista 2019).

Virgi, [...] meu filho, meu marido, já pegaram panema. Mas eles mesmos faziam os remédios deles, banho de folha fede do mato, de pião roxo (MARIA 82, entrevista 2019).

Para melhorar tem que fazer banho forte de pião-roxo, mucuracaá5, pra se livrar da panema (ESPERANÇA 85, entrevista 2019).

No processo de cura para a "panema" se usa: a reza, ervas medicinais, folhas não identificadas do mato, por meio de banhos ou defumações. Os agentes sociais falam para quem está disposto a aprender, pois o saber tradicional não é uma imposição. Ademais, tem quem acredite nele e orientem suas vidas por ele, mas há quem não dê nenhuma significação a essa categoria. Essa é a forma de explicarem o mundo tão válida quanto o saber institucionalizado. Essa categoria êmica, que perpassa pela experiência perceptiva dos agentes sociais, em Merleau-Ponty (1999, p. 355) percebemos que ele destaca que "Sou eu quem tem a experiência, mas tenho consciência, nessa experiência, de assumir uma situação de fato, de reunir um sentido esparso por todos os fenômenos e de dizer aquilo que eles querem dizer de si mesmos".

Nesse sentido, indaga-se: Por que é importante compreendermos essas modalidades enunciativas? É dessa forma que começamos a entender o que faz um discurso se destacar, muitos até a provocar um efeito de verdade circunscrito a um determinado universo social e, consequentemente, produzir uma ação, ao nível de suscitar outros discursos e ao gerar novas materialidades. O saber tradicional visto, a partir de modalidade enunciativas, faz-nos compreender a forma como esses saberes são reproduzidos e produzem materialidades.

\footnotetext{
${ }^{4}$ Outros nomes populares: Cipó-escova, escovinha. Nome científico: Entada polyphyl a Benth. A gipoóca é um cipó do tipo trepador, lenhoso, sem espinhos, mas com gavinhas, de crescimento indeterminado, vigoroso. Cresce utilizando outras plantas como suporte, em altura de 4 a $6 \mathrm{~m}$. As folhas são compostas com quatro pares de folíolos, constituídos por numerosos folíolulos miúdos (SOUZA, 2012, p. 16).

${ }^{5}$ Nome científico: Petiveria alliacea L. Princípios ativos: Óleo essencial, Pitiverina, resina inerte, ácido resinoso, glicose. No Brasil colônia, atribuía-se a essa planta um alto poder de intoxicação, levando a pessoa que a ingeria à afasia ou à morte. Disponível em:
} 
As explicações percebidas da qual a ciência é a experiência, segundo (MERLEAU-PONTY, 1999), não suprimem a forma como os agentes sociais de comunidades ribeirinhas da Amazônia explicam o mundo vivido. Ou seja, não é o cansaço que faz com que o pescador não pegue o peixe, é a força da "panema", de um micropoder que é exterior ao corpo, é uma força sentida que os agentes sociais da comunidade Nossa Senhora Aparecida do Miriti têm, isto é, algo que se manifesta a partir de suas experiências vividas. Eles sentem que há um poder manifestado nessas relações e não se arriscam a negar sua existência, ou ainda, seja algo da imaginação.

\section{A PANEMA E SUA RELAÇÃO COM A CATEGORIA GEOGRÁFICA LUGAR}

Para Foucault (1979), não podemos ter o poder, mas exercê-lo. As instituições como as igrejas, as escolas e outras são vistas por Foucault (1979) como detentoras de um "micropoder", exercido sobre as pessoas, influenciando nas suas capacidades de tomada de decisões, interferindo desde a forma como pensam ou agem em sociedade. Conforme Foucault (1979), o Estado não é a única instituição que detém o poder e faz uso dele.

A partir da pesquisa realizada sobre "Saberes Tradicionais e o Ensino de Ciências: um estudo de caso na comunidade ribeirinha Nossa Senhora Aparecida do Miriti - Parintins/AM", percebemos que, em comunidades amazônicas, os agentes sociais experenciam crenças e micropoderes que exercem forte influência, na forma como eles se relacionam com a natureza, como é o caso demonstrado da "panema".

No diálogo com a ideia de modalidade enunciativas pensadas por Foucault (2008), buscamos responder o problema deste estudo: há possibilidade de trabalharmos o conceito da categoria geográfica lugar, a partir do saber tradicional da "panema"? Chegamos à conclusão que sim, a partir da compreensão da "panema" como uma forma de "micropoder" que faz sentido para o povo que vive em determinado lugar e nela acredita.

A partir da organização do saber cosmológico presente por meio do relato dos agentes sociais que organizamos como modalidades enunciativas, verificamos que podemos classificar a "panema" como um micropoder 
(FOUCAULT, 1979). Com efeito, a categoria geográfica "Iugar", conceituada no ensino a partir do sentido de pertencimento e de relações humanas, foi compreendida por nós como possível de ser também entendida a partir de relações não-humanas, de um micropoder como a "panema".

No ensino de geografia, o estudo das categorias perpassa primeiro pelo seu objeto de estudo que é o espaço geográfico, do qual, como destaca Corrêa (2001), existem diversas definições elaboradas, de acordo com as correntes $^{6}$ geográficas, mas, em geral, refere-se ao que é habitado e transformado pela sociedade decorrente de conflitos, sobretudo aqueles relacionados à sobrevivência.

A categoria região é marcada pelas semelhanças entre os aspectos econômicos, naturais, sociais e culturais. A categoria território corresponde a uma reprodução a partir do espaço, isto é, algo para Raffestin (1993) compreendido a partir das relações de poder, ainda mais quando o homem ocupa um espaço concreto ou abstrato; logo, ele o "territorializa".

A categoria paisagem é descrita como "Tudo aquilo que nós vemos, o que nossa visão alcança, é a paisagem. Esta pode ser definida como o domínio do visível, aquilo que a vista abarca (SANTOS, 1994, p. 21).

Por fim, a categoria lugar, em que a autora Ana Fani Carlos (2007, p. 17) faz um questionamento, antes de conceituá-la, explica que: "Como o homem percebe o mundo? É através de seu corpo de seus sentidos que ele constrói e se apropria do espaço e do mundo. O lugar é a porção do espaço apropriável para a vida - apropriada através do corpo - dos sentidos" (CARLOS, 2007, p. 17).

Segundo Corrêa (2001, p. 30), foi na corrente geográfica Humanista ou Cultural que a categoria "lugar" se tornou o conceito central na discussão da ciência da Geografia, em que se que privilegia "o singular e não o particular ou o universal e, ao invés da explicação, tem na compreensão o base de inteligibilidade no mundo real". Nesse sentido, os princípios nos quais se assentam essa corrente geográfica envolve a "subjetividade, intuição,

\footnotetext{
6 As correntes geográficas são classificadas em: determinismo, possibilismo, regionalismo, Geografia pragmática e Geografia crítica e Geografia Humanista ou Cultural.
} 
sentimentos, experiências, simbolismo e contingência" (CORRÊA, 2001, p. 30). Dessa forma, evidenciam as relações subjetivas que ocorrem entre o homem e o espaço, isto é, orienta-se, sobretudo, pelo sentimento de pertencimento ao lugar.

É na categoria geográfica "lugar" que os agentes sociais vivem suas relações afetivas e sociais, portanto podem nos revelar diferentes aspectos sobre a cultura, modos de vida, economia, história e outras características de uma sociedade. É justamente a união de diferentes lugares como um "somatório das dimensões simbólicas, emocionais, culturais, políticas e biológicas" (BUTTIMER, 1985 apud LEITE, 1998, p.10) que forma o objeto de estudo da Geografia, compreendido como o espaço geográfico.

Em outras palavras, é no lugar que o estudante se relaciona com diferentes contextos sociais e onde as relações de identidade e pertencimento são construídas. Daí a importância de aproximarmos a realidade de cada estudante, por meio de articulações ao seu mundo de vivências, de modo a demonstrar que suas experiências correspondem a uma forma de como o mundo é destacado e vivido por eles. Para Santos (1994, p. 35), "O lugar é um ponto do mundo onde se realizam algumas das possibilidades deste último. O lugar é parte do mundo e desempenha um papel em sua história".

Foucault (1979) esclarece que é equivocado rotular o poder como essencialmente repressivo, e percebemos que podemos adicionar um conceito de "lugar" na geografia, a partir de uma percepção não-humana de micropoder, tendo como referência a "panema" de forma positiva, pois, é uma relação com o mundo não-humano que perpassa por experiências que influenciam fortemente no modo de vida, no respeito pelo lugar que habitam e pelos saberes relacionados à água, à terra e à floresta contidos nesse lugar de vida. Mas, é também um poder do mundo humano, pois são os próprios moradores da comunidade os responsáveis pelas suas leituras. A respeito dos micropoderes, Foucault $(1979$, p. 30) destaca que "finalmente, não são unívocas; definem inúmeros pontos de luta, focos de instabilidade 
comportando cada um com seus riscos de conflito, de lutas e de inversão pelo menos transitória da relação de forças".

Dessa forma, propondo a releitura da categoria geográfica lugar para estudantes de escolas de comunidades amazônicas, vamos de encontro com a proposta da Base Nacional Comum Curricular (BNCC) que propõe estimularmos o pensamento espacial, atrelado ao raciocínio geográfico. "Para fazer a leitura do mundo em que vivem, com base nas aprendizagens em Geografia, os alunos precisam ser estimulados a pensar espacialmente, desenvolvendo o raciocínio geográfico" (BRASIL, 2017, p. 359).

Desta forma, destacamos a possibilidade de articulação entre a categoria geográfica "lugar", a partir do micropoder da "panema" no ensino de geografia. Por sua vez, os territórios de reafirmações históricas, culturais e sociais modificam a prática cotidiana em comunidades ribeirinhas amazônicas. Nesse sentido, recomendamos considerar os conhecimentos locais do lugar e relacioná-los ao ensino de geografia, sobretudo a partir da ideia da "panema", um elemento constituinte do mundo da vida na Amazônia, sobretudo daquelas vidas em constante contato com a água, a terra e a floresta e com as formas de expressões de seus micropoderes.

\section{CONCLUSÃO}

A pesquisa se deteve a conhecer a categoria êmica "panema", a partir de um estudo realizado na comunidade Nossa Senhora Aparecida do Miriti, no município de Parintins, AM, Brasil.

A experiência de realizar pesquisa em comunidade amazônica com agentes sociais adultos nos fez perceber que a ciência ocidentalizada não é a única que produz saber, e estão presentes na cultura de diferentes povos, como foi o caso da pesquisa em questão. Nessa perspectiva, teve como método de abordagem a fenomenologia como uma forma de compreender o saber relativo à "panema", para o ensino de Geografia.

A pergunta de pesquisa desse artigo visou responder: Há possibilidade da categoria geográfica "Iugar", ser significada a partir do saber tradicional da "panema", como um micropoder? Chegamos à conclusão que sim, e as 
modalidades enunciativas de Foucault (2008) nos ajudaram a compreender - discurso desses agentes sociais que são saberes, em sua maioria, caracterizados como não-científicos. Compreendemos que o entendimento desse conceito pode ser tratado na categoria geográfica "lugar", além do sentido de pertencimento, como um micropoder quando falamos da categoria amazônica "panema".

Para o ensino de geográfica a partir do conceito de lugar, destacamos a possibilidade de que os entendimentos dos entrevistados sobre os efeitos da "panema" atendem pela necessidade de caracterização que a geografia cultural atribui como elementos fundantes do lugar. Dessa forma, é possível construir saberes geográficos, a partir de realidades próximas ou vividas pelos próprios alunos da comunidade onde a pesquisa foi realizada. Logo, o lugar comporta o entendimento das relações humanas e relações não humanos. Nesse caso, os efeitos da "panema" na vida são suficientemente claros para sustentar a ideia de que os limites geográficos vividos são mais do que territórios compreendidos pelos seus limites, são lugares com suas representatividades culturais.

\section{REFERÊNCIAS}

ALMEIDA, A. W. B. de. Conhecimento tradicional e biodiversidade: normas vigentes e propostas. (Doutorado em Sociedade e Cultura) - Fundação Universidade do Amazonas, Manaus/AM, 2008.

BRANDÃO, G. da S. Saberes Tradicionais e o Ensino de Ciências: um estudo de caso na comunidade ribeirinha Nossa Senhora Aparecida do Miriti Parintins/AM. Dissertação (Mestrado em Educação em Ciências na Amazônia) - Escola Normal Superior, Universidade do Estado do Amazonas, Manaus/AM 2019.

BRASIL. Ministério da Educação. Base Nacional Comum Curricular. Homologado pelo Conselho Nacional de Educação (CNE) em 20 de dezembro de 2017. Disponível em: http://basenacionalcomum.mec.gov.br/images/BNCC_El_EF_110518_versaofi nal site.pdf. Acesso em: ago. de 2021.

CARLOS, A. F. A. O lugar no/do mundo. São Paulo: Labur Edições, 2007. 
CORREAA, R. L. Espaço, um conceito-chave da Geografia. In: CASTRO, Iná Elias de. GOMES, Paulo César da Costa. CORRÊA, Roberto Lobato (Org.). Geografia: conceitos e temas. Rio de Janeiro: Bertrand Brasil, 2001.

FOUCAULT, M. A arqueologia do saber. Tradução: Luiz Felipe Baeta Neves. Rio de Janeiro: Forense Universitária, 2008.

FOUCAULT, M. Microfísica do poder. Rio de Janeiro: Paz e Terra, 1979.

GALVÃO, E. Panema: uma crença do caboclo amazônico. Revista do Museu Paulista, nova série, vol. 1. São Paulo: O papel, 1951.

IBGE, Instituto Brasileiro de Geografia e Estatística. Parintins. Rio de Janeiro: IBGE, 2019. Disponível em:

https://cidades.ibge.gov.br/brasil/am/parintins/panorama. Acesso em: 14 fev. 2019.

LEITE, A. F. O lugar: duas acepções geográfica". Anuário do Instituto de Geociências, vol 21. Rio de Janeiro, 1998, p. 9-20.

MERLEAU-PONTY, M. Fenomenologia da percepção. São Paulo: Martins Fontes, 1999.

RAFFESTIN, C. Por uma geografia do poder. Tradução de Maria Cecília França. São Paulo: Ática, 1993.

SANTOS, M. Metamorfose do espaço habitado, fundamentos Teórico e metodológico da geografia. Hucite: São Paulo 1994.

SOUZA, L. A. G. de. Leguminosas para adubação verde na terra firme e na várzea da Amazônia Central: um estudo em pequenas propriedades rurais em Manacapuru. Manaus: Editora INPA, 2012.

Recebido em: 25 de agosto de 2021. Aprovado em: 04 de novembro de 2021. Publicado em: 20 de novembro de 2021. 